\title{
Antimicrobial potential of Stevia rebaudiana leaves extract against selected bacterial and
} fungal strains

\author{
Sumbal Bibi ${ }^{1}$, Sumaira Sarwar ${ }^{2}$, Maimoona Sabir ${ }^{1}$, Sobia Nisa ${ }^{1}$, Tabeer Khan ${ }^{1}$ \\ ${ }^{1}$ Department of Microbiology, The University of Haripur, Pakistan \\ ${ }^{2}$ Department of Biochemistry, Islamabad Medical and Dental College, Pakistan \\ Corresponding author Email: monasabir@uoh.edu.pk
}

\begin{abstract}
The antimicrobial potential of leaves extract of indigenous Stevia rebaudiana is investigated to treat infectious diseases. For this purpose, leaf extracts were prepared in two solvents, ethanol and water. The crude extract was tested against four bacterial and one fungal strain (Aspergillus flavus). Out of four bacterial strains, two were gram-positive, Staphylococcus aureus and Lactobacillus acidophilus, whereas Salmonella typhi and Escherichia coli were gram negatives. Clarithromycin and erythromycin were used as a positive control for bacterial growth. However, Terbinafine was used as a positive control against fungal strain, while DMSO was used as a negative control. Results showed that the ethanolic extract of Stevia showed higher antibacterial activity as compared to water extract against all the bacterial strains. The zone of inhibition against E.coli was $5.66 \mathrm{~mm}$. Lactobacillus acidophilus clear zone of inhibition in the ethanolic extract was $9.3 \mathrm{~mm}$. Similarly, the ethanolic extract of leaves showed inhibition against Staphylococcus aureus and Salmonella typhi, with an average zone of inhibition $(7.33 \mathrm{~mm}$ and $7.66 \mathrm{~mm})$. These findings suggested that leaves extracts have inhibitory activities against bacterial strains, although their antibacterial activities are lower than that of the standard that is Clarithromycin and Erythromycin. Leaves extract of Stevia showed no activity against Aspergillus flavus. It was concluded that Stevia rebaudiana ethanolic extract could be used as an antibacterial agent against selected pathogens due to its significant activity. In contrast, no significant activity against fungal pathogen was observed in both extracts.
\end{abstract}

Keywords: ,Stevia rebaudiana, infectious diseases, Aspergillus flavus, DMSO

\section{Highlight:}

$\checkmark$ treatment of infectious diseases through leaf extract of indigenous Stevia rebaudiana

$\checkmark$ ethanolic extract of Stevia showed higher antibacterial activity as compared to water extract

$\checkmark$ no significant activity against fungal pathogen

\section{Introduction}

With the advancement in urbanization and globalization, the rate of infectious diseases also increased. These infectious diseases became the primary cause of morbidity and mortality in developing countries. The discovery and effectiveness of antimicrobial agents have become a significant issue due to the emergence and dissemination of multidrug-resistant strains (Giamarellou, 2010; Shaik et al., 2014). Most bacterial strains possess the genetic ability to gain and transfer-resistant genes against antimicrobial agents. Bacteria possess several resistant mechanisms like the presence of efflux pumps, site/surface modification, and metabolic inactivation (Hooper, 2001; Yala et al., 2001). The primary reason for developing resistance among the bacterial strains is incorrect and excessive antibiotic usage; therefore, developing alternative drugs or antimicrobial agents against multidrug-resistant pathogens is in dire need (Elisha et al., 2017). There is a need to develop antimicrobial drugs from medicinal plants to treat several diseases (Clark, 1996; Binutu, and Cordell, 2000)..

Using medicinal plants to treat infectious diseases caused by microorganisms is an old practice, and various phytotherapeutic products are also used to treat many infectious diseases. Sometimes an infection in a human causes a severe problem caused by pathogenic microorganisms such as bacteria and fungi. In recent years these infections in the immune-compromised individual have significantly increased, and these infections include many risk factors such as leucopenia, neutropenia, hepatotoxicity, and tissue lesions (Dolande et al., 2002; Mottl and Wheat, 1994). Due to the random use of commercially available antimicrobial drugs to treat infectious diseases, multiple drug resistance (MDR) has been developed (Davis, 1994; Pitt. et al., 1995). Owing to this problem, sometimes antibiotics show harmful effects on the host, such as immune suppression, hypersensitivity, and many allergic reactions (Ahmed et al., 2014). Therefore researchers shifted their interest to low-cost, biocompatible alternatives with the most negligible side effects. Plant-based antimicrobial products can act as an alternative and effective treatment method for different infectious diseases.

Medicinal plants consider a valuable source in modern and traditional medicines (Dey et al., 2013). According to the World Health Organization (WHO) $80 \%$ of the world population depends on herbal medication (Mukeshwar et al., 2011). Plants naturally contain many phytochemicals and secondary metabolites such as glycosides, terpenoids, saponins, steroids, flavonoids, tannins, quinones, and coumarins which act as natural/plant-derived antimicrobial substances (Danlami, and Elisha., 2017). Due to plants' natural potential, there is a need to explore different species that can combat diseases and have antimicrobial potential. 
Stevia is a genus of approximately 200 species of shrubs and herbs. Stevia rebaudiana is a perennial shrub that belongs to the sunflower family (Asteraceae). It is referred to as the "sweet herb of Paraguay" because it was native to a specific region of South America like Brazil and Paraguay. The major sweet component of Stevia rebaudiana is present in its leaves which contain stevioside, and its taste is about 300 times sweeter than sucrose. Therefore it is a $100 \%$ natural source of flavor enhancers and non-fermentable things. It is used for sweeteners in soft drinks, pickles, skincare products, ice-creams, and soya sauce. There will be a high need for natural sweeteners in the food market (Gupta et al., 2014) in the future. The leaves contain a mixture of eight sweet diterpene glycosides, including stevioside, steviolbioside, rebaudioside, and dulcoside $\mathrm{A}^{2}$. Stevia also contains bioactive compounds such as essential oil, flavonoids, and tannins. Stevia rebaudiana has been made health benefits both externally and internally due to the whole extract of its leaves (Abou-Arab, \& AbuSalem, 2010).

Previously antimicrobial activities of various herbs and spices in plants leaves, flowers, stems, roots, and fruits have been reported. Some studies investigated the antimicrobial activity of various extracts of Stevia rebaudiana (with chloroform, ethyl acetate, water, hexane, or acetone as solvent) against some selected microorganisms such as Bacillus subtilis, Salmonella typhi, Vibrio cholera, Staphylococcus aureus, and others have been examined (Debnath, 2008; Ghosh et al., 2008; Jayaraman et al., 2008; Tiwari, 2010 and Tadhani et al.,2006). Many biomedical properties of Stevia rebaudiana have also been reported, including antibacterial, antioxidant, antifungal, anti-diabetic, hyperglycemic, hypertensive, antimicrobial, and anti-inflammatory (Goyal et al.,2010; Akash et al., 2015).

Pakistan has a large diversity of plant species containing many bioactive compounds which can be explored and used against different diseases. Due to the medicinal properties of Stevia rebaudiana leaves have very high demand in the world; regarding Pakistan, There is limited research on antimicrobial activity of Stevia leaves is reported; therefore, the current study was conducted to evaluate the antimicrobial activity of Stevia leaves.

The study aimed to evaluate the antimicrobial activity of Stevia rebaudiana leaves extract against Gram-positive, and Gram-negative bacterial strains (Staphylococcus aureus, Salmonella typhi, Lactobacillus acidophilus, Escherichia coli) and fungal strain (Aspergillus flavus), followed by a comparison of the antimicrobial efficacy of stevia leaves with commercial antibiotics.

\section{Material and methods}

The current research work was conducted in the Department of Microbiology, University of Haripur, Khyber-Pakhtunkhwa, Pakistan. Media used in the study were purchased from Merck, Muller Hinton agar (Merck, NutriSelect Plus) was used for antibacterial activity, while potato dextrose agar (Merck, NutriSelect Plus) was used for fungus growth.

Test pathogens including Staphylococcus aureus, Salmonella typhi, Lactobacillus acidophilus, Escherichia coli, and Aspergillus flavus were obtained from the microbiology laboratory of Quaid-e-Azam University, Islamabad. Pakistan.

\subsection{Collection of Plant material}

Stevia rebaudiana leaves were collected from National Agriculture Research Centre (NARC), Islamabad. Collected leaves were washed with running tap water, washed with sterile water, and then dried in an oven at $40{ }^{\circ} \mathrm{C}$ for 4 days. Then leaves were finely powdered using mortar, vortex, and stored in airtight bottles ((Fig. 1) while identification of the plant reprted in Table 1.
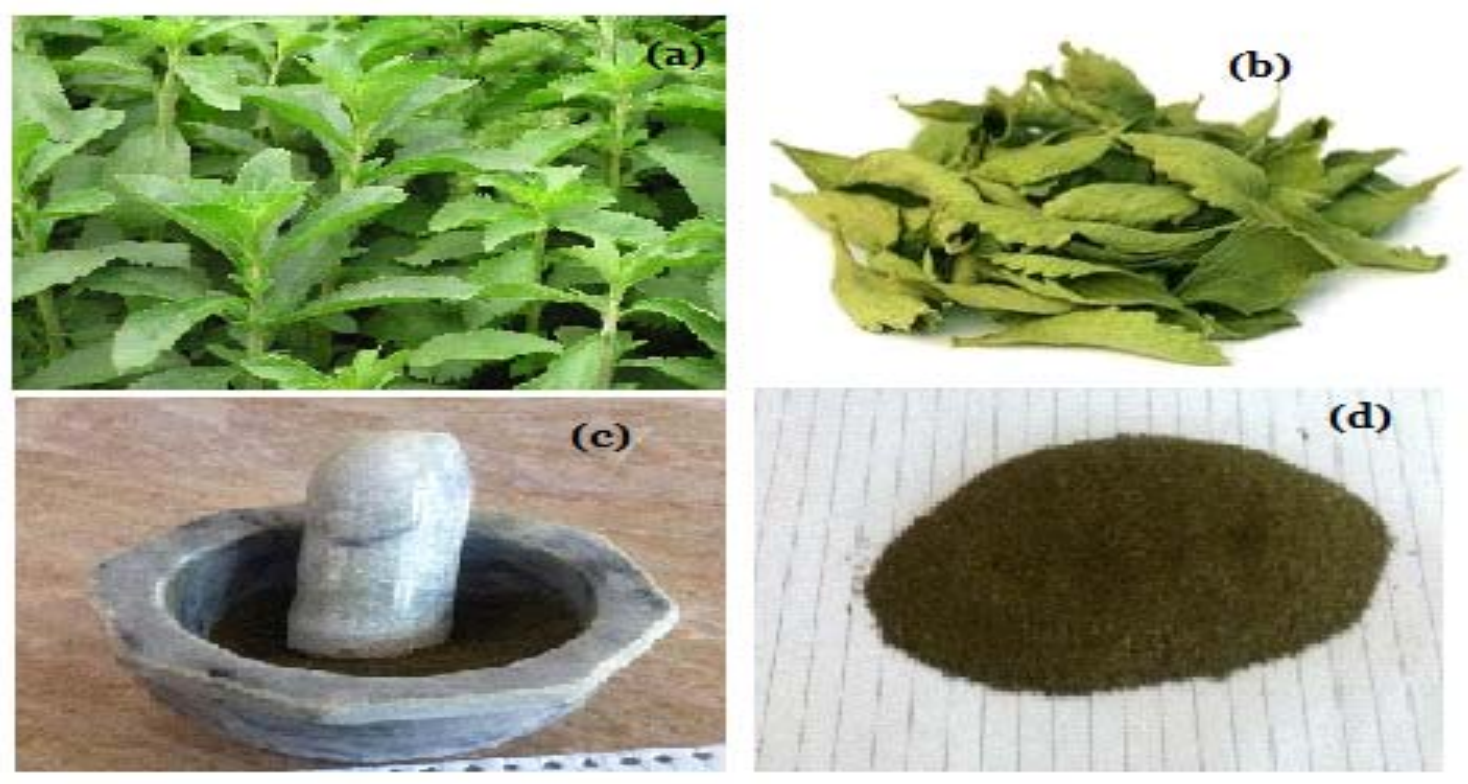
Figure. 1: (a) Field photograph of Stevia rebaudiana (National Agriculture Research Institute, Islamabad). (b) Dried leaves of Stevia rebaudiana (c) Stevia rebaudiana leaves powder made by mortar and piston (d) Dried leaves powder of Stevia rebaudiana.

Table: 1 Classification of Stevia

\begin{tabular}{ll}
\hline Kingdom & Plantae Plants \\
\hline Subkingdom & Tracheobionta - Vascular plants \\
Super division & Spermatophyta - Seed plants \\
Division & Magnoliophyta - Flowering plants \\
Class & Magnoliopsida - Dicotyledons \\
Subclass & Asteridae \\
Order & Asterales \\
Family & Asteraceae - Aster family \\
Genus & Stevia Cav. - candy leaf \\
Species & Stevia rebaudiana (Bertoni) Bertoni candyleaf \\
\hline
\end{tabular}

Source: Stevia rebaudiana (Bertoni) Bertoni, National Plant Data Center

\subsection{Preparation of Plant extract (Stevia rebaudiana)}

Dried powdered of Stevia rebaudiana were immersed in ethanol and distilled water separately in falcon tubes (conc. $100 \mathrm{mg} / \mathrm{mL}$ ). It was incubated at room temperature for 48 hours at $150 \mathrm{rpm}$ in an orbital shaker. The prepared plant extract was filtered through filter paper.

\subsection{Antibacterial Activity of Stevia rebaudiana}

This bioassay was employed for testing the antibacterial activity of leaves of Stevia rebaudiana. This assay was performed by the disc diffusion method in Muller Hinton agar plates. After this, the pure bacterial strains were spread on solid agar plates with a sterile swab. With the help of sterile forceps, the sterile filter paper disc of ethanol and water extract of Stevia was laid down on the surface of agar plates containing a bacterial culture. Then, the positive control (clarithromycin and erythromycin) and negative control (DMSO) discs were placed on the agar plates. The plates were incubated at $37^{\circ} \mathrm{C}$ for 24 hours. After this, the zone of inhibition was measured in $\mathrm{mm}$, around the disc to check the antibacterial activity.

\subsection{Antifungal activity of Stevia rebaudiana}

In this bioassay, Potato dextrose agar was used. The media was prepared and poured into Petri plates. After solidification, the pure fungal strain was spread on Petri plates, and then with the help of sterile forceps, the disc of ethanol and water extract of Stevia was also placed on the plates. In contrast, Terbinafine was used as a positive control, and DMSO was used as a negative control. The plates were incubated at $25{ }^{\circ} \mathrm{C}$ for 4 days. The antifungal activity was determined by measuring the zone of inhibition (Rajeh et al., 2010).

\subsection{Statistical analysis}

The zone of inhibition was measured with the help of scale in $\mathrm{cm}$ then the centimeters were converted into millimeters $(1 \mathrm{~cm}$ $=10 \mathrm{~mm})$. Statistical analysis was done with MS Excel, and experimental values were represented as mean \pm SEM.

\section{Results}

The ethanolic and water extracts of Stevia rebaudiana leaves were used for the current study against fou rbacterial strains (Staphylococcus aureus,Escherichia coli, Lactobacillus acidophilus, Salmonella typhi) and one fungal strain (Aspergillus flavus). DMSO was used as a negative control. Erythromycin and clarithromycin were used as a standard control for bacterial strains. While terbinafine, the antifungal disc was also used as a standard control for fungal strain.

\subsection{Antibacterial Activity of Stevia rebaudiana}

After 24 hours, Stevia showed its activity against E. coli. It was observed that ethanol extract of Stevia showed a zone of inhibition against E. coli which was $5.66 \mathrm{~mm}$; the zone of inhibition observed was $3.00 \mathrm{~mm}$. Antibiotics clarithromycin and erythromycin, used as the positive control, showed the highest activity against E.coli with a zone 
of inhibition recorded at $9.66 \mathrm{~mm}$ and $5.33 \mathrm{~mm}$, respectively (Table 2). Clarithromycin showed higher activity against E. coli, ethanol extract of Stevia and erythromycin showed moderate activity, and water extract of Stevia showed lower activity. DMSO showed no activity, which was used as a negative control (Fig. 2).

Table 2: Antibacterial activity of Stevia rebaudiana against Bacterial pathogens

\begin{tabular}{llllll}
\hline $\begin{array}{l}\text { Bacteria } \\
\text { strain }\end{array}$ & $\begin{array}{l}\text { Ethanol } \\
\text { extract }\end{array}$ & $\begin{array}{l}\text { Water } \\
\text { extract }\end{array}$ & Clarithromycin & Erythromycin & DMSO \\
\hline E. coli & $5.66 \pm 0.33$ & $3.00 \pm 0.00$ & $9.66 \pm 0.33$ & $5.33 \pm 0.33$ & $0.00 \pm 0.00$ \\
L. acidophilis & $9.33 \pm 0.54$ & $2.66 \pm 0.27$ & $9.33 \pm 0.27$ & $8.33 \pm 0.27$ & $0.00 \pm 0.00$ \\
S. aureus & $7.33 \pm 0.33$ & $3.66 \pm 0.33$ & $12.33 \pm 0.33$ & $11.00 \pm 0.57$ & $0.00 \pm 0.00$ \\
S. typhi & $7.66 \pm 0.66$ & $1.66 \pm 0.33$ & $6.33 \pm 0.33$ & $6.66 \pm 0.33$ & $0.00 \pm 0.00$ \\
\hline
\end{tabular}

*Shows mean zone of inhibition in $\mathrm{mm} \pm \mathrm{SEM}$

It was further observed that both ethanol and water extract of Stevia showed inhibitory activity against Lactobacillus acidophilus. Table 2 showed the mean diameter of the clear zone of inhibition of ethanol extract (9.3 $\mathrm{mm})$ and water extract was $2.6 \mathrm{~mm}$. The antibiotic disc that was used as a standard control also showed a zone of inhibition against Lactobacillus acidophilus. Table 2 showed that the mean diameter of the clear zone of clarithromycin inhibition was $9.3 \mathrm{~mm}$, and erythromycin was $8.3 \mathrm{~mm}$. Consequently, it was observed that ethanol extract and antibiotics disc (Clarithromycin and Erythromycin) showed a higher zone of inhibition while water extract showed significantly lower activity against Lactobacillus acidophilus (Figure 2).
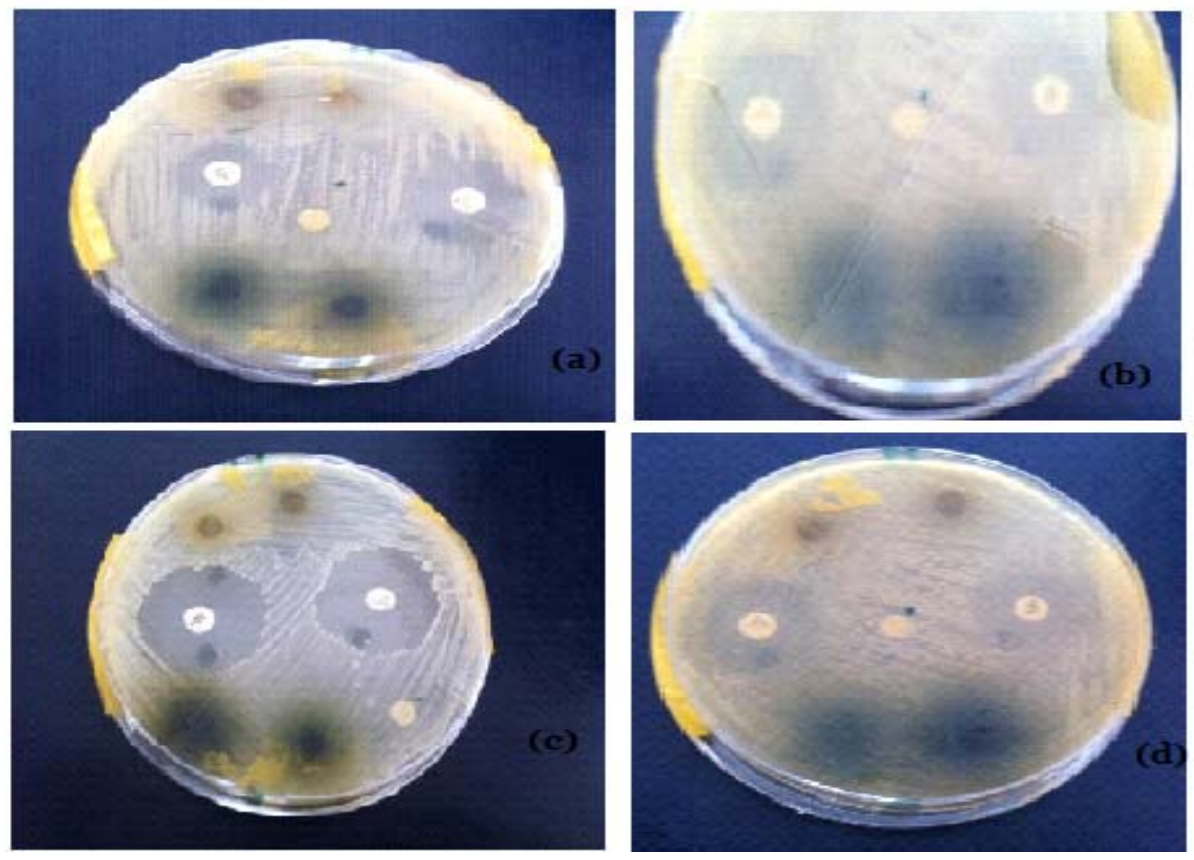

Figure. 2: (a) Plate showing zone of inhibition against E. coli. (b) Plate showing zone of inhibition against Lactobacillus acidophilus. (c) Plate showing zone of inhibition against $S$. aureus (d) Plate showing zone of inhibition against $S$. typhi

Significant antibacterial activity of Stevia rebaudiana was observed against Staphylococcus aureus. After 24 hours, ethanol extract of Stevia showed a zone of inhibition of $7.33 \mathrm{~mm}$, and water extract of the plant showed a zone of inhibition of $3.66 \mathrm{~mm}$, while the positive control Clarithromycin and Erythromycin showed zone of inhibition of $12.33 \mathrm{~mm}$ and $11 \mathrm{~mm}$ (Table 2). In (Fig. 2), the antibiotic disc showed higher activity against S. aureus while ethanol and water extract showed lower activity against $S$. aureus than the antibiotic disc. Further, it was observed that after 24 hours, ethanolic and water extracts of Stevia exhibited antimicrobial activity and the zone of inhibition observed were $7.6 \mathrm{~mm}$ and $1.66 \mathrm{~mm}$, respectively. While, an antibiotic disc of Clarithromycin and Erythromycin showed a zone of inhibition of $6.33 \mathrm{~mm}$ and $6.66 \mathrm{~mm}$ (Table 2, Figure 2). In (Table 2), the ethanol extract showed higher activity against Salmonella typhi and positive control antibiotic disc of Clarithromycin and Erythromycin showed moderate activity, and water extract of Stevia showed lower activity against $S$. typhi. 


\subsection{Antifungal Activity of Stevia rebaudiana}

The antifungal activity Stevia rebaudiana showed that both ethanolic and water extracts exhibit no activity against Aspergillus flavus. Similarly, Terbinafine also showed no activity against Aspergillus flavus (Table 3, Fig. 3).

Table 3: Antifungal activity of ethanol and water extract of Stevia rebaudiana against Aspergillus flavus

\begin{tabular}{lllll}
\hline Fungal strain & Ethanol extract & Water extract & Terbinafine & DMSO \\
\hline Aspergillus flavus & $0.00 \pm 0.00$ & $0.00 \pm 0.00$ & $0.00 \pm 0.00$ & $0.00 \pm 0.00$ \\
\hline+ SD & & & &
\end{tabular}

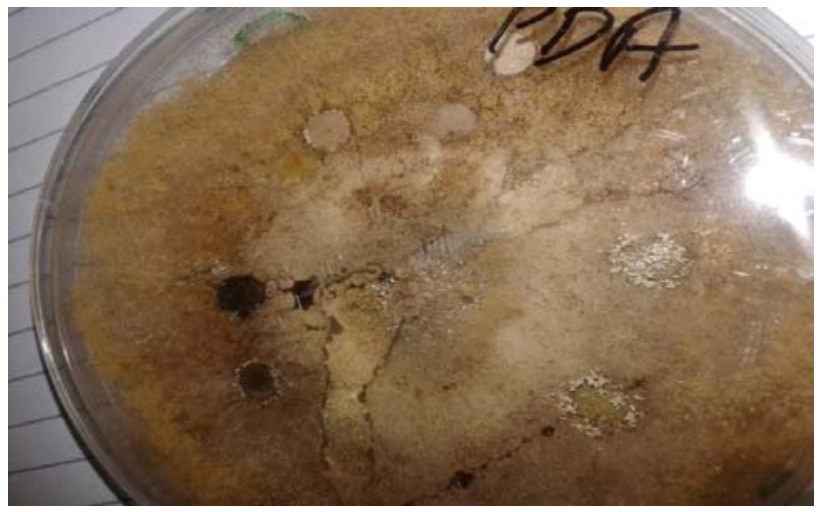

\section{Discussion}

Figure 3: Plate showing activity of Stevia extract against Aspergillus flavus

The plant has been a valuable natural product source for maintaining human health for natural therapies. Plant extracts and phytochemicals have a significant role in therapeutic treatment due to their antimicrobial properties (Santos et al., 1995). According to the world health organization (WHO), the primary source of various drugs is a medicinal plant. $80 \%$ of individuals use traditional medicines (Ellof, 1998) in a developed country.

A previous study reported that Stevia extracts possess antibacterial, anti-yeast, antifungal, and antitumor activity (Tadhani et al., 2006). The aim of the study was to evaluate the antimicrobial activity of ethanolic and water extract of indigenous Stevia rebaudiana against four bacterial strains and one fungal strain. In this study, the antibacterial activity of ethanol and water extract of Stevia was compared with two standard antibiotics (Clarithromycin and Erythromycin). In contrast, the antifungal activity of both extracts was compared with the antifungal drug (Terbinafine). The ethanol extract of Stevia shows the highest activity against four bacterial strains (S. aureus, Lactobacillus acidophilus, S. typhi and E. coli), but water extract of Stevia showed the lowest activity against these strains.

In contrast, the Stevia extracts and Terbinafine showed no activity against fungal strain. The ethanol extract of Stevia showed a zone of inhibition against E. coli, Lactobacillus acidophilus, S. aureus, and S. typhi was $5.66 \pm 0.33,9.33 \pm 0.54$, $7.33 \pm 0.33$, and $7.66 \pm 0.66$. But, the water extract of Stevia showed the lowest zone of inhibition which was 3.00+0.00, $2.66 \pm 0.27,3.66+0.33$, and $1.66+0.33$ (Fig. 4).

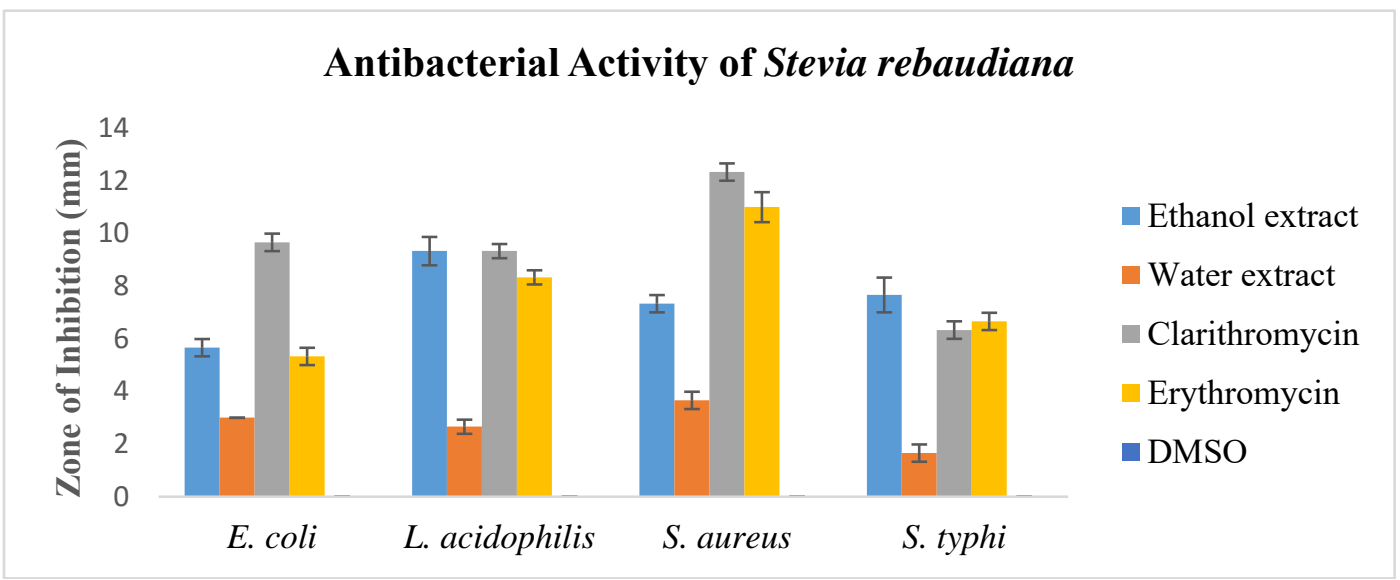

Fig. 4: Comparative antimicrobial activity of Stevia rebaudiana ethanolic extract, water extract, and antibiotics.

The present study is in accordance with the reports of Tadhani et al., (2006), who observed less antibacterial activity of water-based extract of Stevia (Tadhani et al., 2006). Further, many researchers have also reported that the 
water extract did not show higher activity against pathogenic bacteria (Vlietinck et al., 1995). Debnath (2008) also reported that water extract does not show activity against bacterial strain.

The result of ethanol extract of Stevia against Lactobacillus acidophilus was also in accordance with a previous study reported by Gamboa, \& Chaves, (2012). The ethanolic extract of Stevia leaves against E. coli and S. aureus showed almost the same results compared with the study of Ghosh et al.,(2008); the results of Ghosh et al.,(2008) against E. coli and S. aureus was $5 \mathrm{~mm}$, but the present study showed zone of inhibition of $5.66 \mathrm{~mm}$ and $9.33 \mathrm{~mm}$. According to Malik et al., (2011) the higher activity of ethanol extract is due to the more excellent solubility of extract in the organic solvent, or this could be due to the concentration of the active substances. These findings suggested that leaves extracts of Stevia exhibited a significant amount of antibacterial agents. Therefore it is suggested that these leaves extracts could be used for remedial purposes against selected bacterial pathogens. Further, a dose-dependent study of crude extract of Stevia leaves and in vitro evaluation of antimicrobial activity against different pathogens is required.

\section{Conclusion}

The present research was conducted to evaluate the antimicrobial activity of ethanol and water extract of Stevia rebaudiana against four bacterial strains (Staphylococcus aureus, Salmonella typhi, Lactobacillus acidophilus, and Escherichia coli) and one fungal strain (Aspergillus flavus). From this study, it was concluded that Stevia has antibacterial activity. The ethanol extract is more effective than the water extract of Stevia. The overall results of the present study showed that ethanol extract of the plant showed higher results against bacterial strains than antibiotics, but water extract of the plant showed shallow activity, whereas Stevia showed no activity against fungal strains (Aspergillus flavus). The medicinal plant could be the best source of new antimicrobial compounds; therefore, more study is required to evaluate and purify the new active antibacterial and antifungal constituent.

\section{Acknowledgment:}

The authors highly acknowledged the laboratory of the Department of Microbiology, The University of Haripur, Pakistan, and Department of Biochemistry, Islamabad Medical and Dental college, Pakistan.

\section{Conflict of interest}

The authors reported no potential conflict of interest

\section{References}

Abou-Arab, E. A., \& Abu-Salem, F. M. (2010). Evaluation of bioactive compounds of Stevia rebaudiana leaves and callus. Journal of Food and Dairy Sciences, 1(4), 209-224.

Ahmad, S Farooq, A.K., Abdul, H Muhammad, S.N. (2014). A Review on Potential Toxicity of Artificial Sweeteners vs. Safety of Stevia: A Natural Bio-Sweetener. J. Biol. Agricul. Healthcare. 4: 137-147.

Akash B, Dr. Meenal and Versa K (2015). Phytochemical Screening and antimicrobial activity of Stevia rebaudiana Leaves. Int. J.Curr. Microbiol .App. Sci. 4(10): 678-685.

Binutu, O. A., \& Cordell, G. A. (2000). Gallic acid derivatives from Mezoneuron benthamianum leaves. Pharmaceutical Biology, 38(4), 284-286.

Clark, A. M. (1996). Natural products as a resource for new drugs. Pharmaceutical research, 13(8), 1133-1141.

Danlami, U., \& Elisha, E. P. (2017). A comparative study on the phytochemicals and antimicrobial activities of the ethanol and petroleum ether extracts of the leaves of Albizia Lebbeck and Its Mistletoe. International journal of pharmacy and chemistry, 3(2), 13-18.

Davis, J. L. (1994). The cross-section of realized stock returns: The pre-COMPUSTAT evidence. The Journal of Finance, 49(5), 1579-1593.

Debnath, M. (2007). Clonal propagation and antimicrobial activity of an endemic medicinal plant Stevia rebaudiana. Journal of medicinal plants research, 2(2), 045-051.

Debnath, M. (2007). Clonal propagation and antimicrobial activity of an endemic medicinal plant Stevia rebaudiana. Journal of medicinal plants research, 2(2), 045-051.

Dey A, Kundu SB and Yopadhyay A and Bhattacharjee A (2013). Efficient micropropagation and chlorocholine chloride induced stevioside production of Stevia rebaudiana Bertoni. Comptesrendusbiologies.336 (1): 1728.

Elisha, I. L., Botha, F. S., McGaw, L. J., \& Eloff, J. N. (2017). The antibacterial activity of extracts of nine plant species with good activity against Escherichia coli against five other bacteria and cytotoxicity of extracts. BMC complementary and alternative medicine, 17(1), 1-10. 
Ellof, J. (1998). A sensitive and quick microplate method to determine the minimal inhibitory concentration of plant extracts for bacteria. Planta Medica, 64(8), 711-713

Gamboa, F., \& Chaves, M. (2012). Antimicrobial potential of extracts from Stevia rebaudiana leaves against bacteria of importance in dental caries. Acta odontológica latinoamericana, 25(2), 171-175.

Ghosh, S., Subudhi, E., \& Nayak, S. (2008). Antimicrobial assay of Stevia rebaudiana Bertoni leaf extracts against 10 pathogens. International Journal of Integrative Biology, 2(1), 27-31.

Ghosh, S., Subudhi, E., \& Nayak, S. (2008). Antimicrobial assay of Stevia rebaudiana Bertoni leaf extracts against 10 pathogens. International Journal of Integrative Biology, 2(1), 27-31.

Giamarellou, H. (2010). Multidrug-resistant Gram-negative bacteria: how to treat and for how long. International Journal of Antimicrobial Agents, 36, S50-S54.

Goyal S, Samsher, Goyal R (2010). Stevia (Stevia rebaudiana) a bio-sweetener. Int. J.Food Sci. Nutr. 61:1-10.

Gupta, R., Yadav, V., \& Rastogi, M. (2014). A review onimportance of natural sweetener, a zero calorie plant-SteviaHaving medicinal and commercial importance. International Journal of Food and Nutritional Sciences, 3(3), 90.

Hooper, D. C. (2001). Emerging mechanisms of fluoroquinolone resistance. Emerging infectious diseases, 7(2), 337.

Jayaraman, S., Manoharan, M. S., \& Illanchezian, S. (2008). In-vitro antimicrobial and antitumor activities of Stevia rebaudiana (Asteraceae) leaf extracts. Tropical Journal of Pharmaceutical Research, 7(4), 1143-1149.

Malik, F., Hussain, S., Mirza, T., Hameed, A., Ahmad, S., Riaz, H., ... \& Usmanghani, K. (2011). Screening for antimicrobial activity of thirty-three medicinal plants used in the traditional system of medicine in Pakistan. Journal of Medicinal plants research, 5(14), 3052-3060.

Mottl, M. J., \& Wheat, C. G. (1994). Hydrothermal circulation through mid-ocean ridge flanks: Fluxes of heat and magnesium. Geochimica et Cosmochimica Acta, 58(10), 2225-2237.

Mukeshwar, P., Debnath, M., Gupta, S., \& Chikara, S. K. (2011). Phytomedicine: An ancient approach turning into future potential source of therapeutics. Journal of Pharmacognosy and phytotherapy, 3(2), 27-37.

Pitt, L. F., Watson, R. T., \& Kavan, C. B. (1995). Service quality: a measure of information systems effectiveness. MIS quarterly, 173-187.

Rajeh, M. A. B., Zuraini, Z., Sasidharan, S., Latha, L. Y., \& Amutha, S. (2010). Assessment of Euphorbia hirta L. leaf, flower, stem and root extracts for their antibacterial and antifungal activity and brine shrimp lethality. Molecules, 15(9), 6008-6018.

Shaik, G., Sujatha, N., \& Mehar, S. K. (2014). Medicinal plants as source of antibacterial agents to counter Klebsiella pneumoniae. Journal of applied pharmaceutical science, 4(1), 135-147.

Santos, A. R., Valdir Filho, C., Yunes, R. A., \& Calixto, J. B. (1995). Analysis of the mechanisms underlying the antinociceptive effect of the extracts of plants from the genus Phyllanthus. General Pharmacology: The Vascular System, 26(7), 1499-1506.

Tadhani, M. B., \& Subhash, R. (2006). In vitro antimicrobial activity of Stevia rebaudiana Bertoni leaves. Tropical Journal of Pharmaceutical Research, 5(1), 557-560.

Tadhani, M. B., \& Subhash, R. (2006). In vitro antimicrobial activity of Stevia rebaudiana Bertoni leaves. Tropical Journal of Pharmaceutical Research, 5(1), 557-560.

Tiwari, S. (2010). Stevia rebaudiana: a medicinal and nutraceutical plant and sweet gold for diabetic patients. International Journal of Pharmacy and Life Sciences (IJPLS), 1(8), 451-457.

Vlietinck, A. J., Van Hoof, L., Totte, J., Lasure, A., Berghe, D. V., Rwangabo, P. C., \& Mvukiyumwami, J. (1995). Screening of hundred Rwandese medicinal plants for antimicrobial and antiviral properties. Journal of ethnopharmacology, 46(1), 31-47.

Yala, D., Merad, A. S., Mohamedi, D., \& Ouar Korich, M. N. (2001). Classification et mode d'action des antibiotiques. Médecine du Maghreb, 91(1), 5-12.

Received: $2^{\text {th }}$ October 2021

Accepted: $30^{\text {th }}$ December 2021 